\title{
The Relationship between Iranian ELT Instructors' Beliefs about Language Teaching and Their Practices in Real Classrooms
}

\author{
Morteza Mellati ${ }^{1}$, Mohammad Ali Fatemi ${ }^{1} \&$ Khalil Motallebzadeh $^{1}$ \\ ${ }^{1}$ Department of English, Torbat-e-Heydareih Branch, Islamic Azad University, Torbat-e-Heydareih, Iran \\ Correspondence: Morteza Mellati, Department of English, Torbat-e-Heydareih Branch, Islamic Azad University, \\ Torbat-e-Heydareih, Iran. E-mail: Mellati.morteza@gmail.com
}

Received: January 27, 2013 Accepted: March 8, 2013 Online Published: March 20, 2013

doi:10.5539/elt.v6n4p126 URL: http://dx.doi.org/10.5539/elt.v6n4p126

\begin{abstract}
Teachers play different roles in multidimensional process of language teaching and their beliefs about language teaching might influence their practices. Donaghue (2003) stated that beliefs guide teachers in their practice. However, Argyris and Schon (1978) claimed that there is almost a discrepancy between teachers' beliefs about language teaching and their practices in the classrooms. Therefore, the present study investigated the relationship between Iranian ELT instructors' beliefs about language teaching and their real practices in classrooms. To achieve this goal, the researchers accidentally selected 369 Iranian ELT instructors and 512 Iranian students. To collect the required data, the researchers employed Teacher's Beliefs Questionnaire (TBQ) to elicit instructors' beliefs about language teaching and Students' Satisfaction Questionnaire (SSQ) to elicit to what extent Iranian instructors applied their beliefs in their practices. Besides, to verify the results of questionnaires, the researchers interviewed nine instructors. The results revealed a positive significant relationship $(\mathrm{p} \leq 0.05)$ between instructors' beliefs about language teaching and their real practices in classrooms. The findings proposed some applicable implications that can be applied by policy makers and curriculum designers to provide facilities to support reflective teaching and to improve teacher education programs.
\end{abstract}

Keywords: teachers' beliefs, teacher education programs, contextual factors, teaching method, teaching design

\section{Introduction}

One of the fundamental steps in every language teaching and learning context is to consider the qualities of successful language teachers and the functions they perform in the process of language teaching and learning (Brown, 2001; Mohamed, 2006; and Awenowicz, 2009). Williams and Burden (1997) identified four key factors which influence this process that are teachers, learners, tasks, and contexts. They asserted that none of these factors exists in isolation and all of them influence learning process simultaneously. However, to understand teacher's roles in language teaching, the researchers have to focus on teacher role in isolation. Tsui (2003) classified teachers' knowledge or beliefs into four categories: teachers' knowledge as reflective practice, teachers' knowledge as personal practical knowledge, teachers' knowledge as suited knowledge, and teachers' knowledge as content knowledge.

\subsection{Statment of the Problem}

Schon (1983), in his work, Reflective Practitioner, criticized the view of professional knowledge expounded in the Technical Rationality Model, which perceived teachers' knowledge having four essential properties: specialized, firmly bounded, scientific, and standardized. Teachers often find themselves in situations that are highly complex and fraught with uncertainty, instability, uniqueness, and value conflict. He argued that they could not simply apply research-based theory to problem solving because problems do not present themselves as given. They have to identify the problem by making sense of situations that are ill defined, messy, and full of uncertainty. Even when the problem has been identified, they may find that the problem is unique; therefore, they could not solve it by applying previous theories or techniques. Dweck (1999) suggested that different teachers create different meaning systems. Teachers create meaning systems in order to explain their own learning, their interactions with others, their understanding of the reasons for success and failure, and most importantly their understanding about themselves. Beliefs about the self have a tremendous effect on the psychological, affective, and cognitive realities of teachers in similar situations (as cited in Hewitt, 2008). Donaghue (2003) stated, “Teachers' beliefs influence the acceptance and uptake of new approaches, techniques, 
and activities, and therefore play an important part in teacher development" (p. 344). Branden (2006) emphasized that recent empirical research has shown that what teachers do in the classroom is not always consistent with what they believe should be or can be done and reasons such as contextual constraints, conflicting beliefs, and conflicts between beliefs and skills are the main factors of this inconsistency. Teachers may be convinced of particular pedagogical approaches on a theoretical level, but lack the skills to put them into practice.

\subsection{Significance of the Study}

Most researchers such as Borg (2001) believed in teachers' central roles in language teaching and believed that teachers' beliefs play important roles in daily life and in many aspects of language teaching. Under the influence of their beliefs, individuals make sense of the world, perceive new information, and accept or reject them. Horwitz (1999) stated, "Teachers have come to view language learners as individuals approaching language learning in their own unique way. As this issue reflects, one of the important areas of current interest about language learners is their beliefs about language learning" (p. 558). Rios (1996) suggested that teachers' beliefs have the most profound and intensive influence on their language teaching process (as cited in Lin, 2010). Liao (2007) argued, "Teachers may derive beliefs from their current teacher training programs or teaching career" (p. 45).

In addition, Schon (1978) argued that there is usually a discrepancy between what professionals say they believe and the ways in which they act. In teaching, if there would be a large discrepancy between a teacher's expressed beliefs and the way in which that teacher acts professionally, then learners are likely to receive confusing messages (as cited in Williams and Burden, 1997).

In every language-teaching context, teachers have different expressed teaching beliefs that influence their decisions and their instructional judgments. Fahim and Samadian (2011) believed that Iran's educational system is based on the Grammar Translation Method (GTM) and this method is not appropriate for Iranian students as well as Iranian language teaching environment. They stated that teachers have to follow their fixed instructional schedules and curriculums. Teachers' beliefs and teachers' knowledge have no or even little role in the complex and multidimensional process of instructional judgments and conducting tasks in their classrooms. Therefore, this study tries to throw light on the relationship between ELT Iranian instructors' beliefs about language teaching and their practices in real classrooms. The current study tries to investigate to what extent Iranian ELT instructors act in accordance with their expressed teaching beliefs.

\subsection{Review of Literature}

Tsui (2003) stated that teachers' beliefs have been given a great deal of attention in teacher education research literature because of their important role in helping teachers to make sense of the complex and multidimensional nature of classroom life, to identify goals, and to shape their evolving perceptions of themselves as teacher.

Vibulphol (2004) stated, "Researchers have found that second language learners come to the language class with some preconceived ideas or beliefs about language and language learning" (p. 1). Kennedy (1997) asserted that teachers' conceptions influence a wide range of teaching practices. He found that those teachers who attend to different principles of teaching looked noticeably different on classroom observations in planning their lessons. Teachers' conceptions of subject matter also influence the way they teach that subject matter. In addition, teachers translate educational innovations into practices that are consistent with their conceptions. Farrell and Particia (2005) focused on the relationship between teachers' beliefs and their practices in the case of teaching grammar. They stated, "Teachers' theoretical beliefs influenced their classroom practices, and found evidence to suggest that what teachers say and do in the classroom are governed by their beliefs" (p. 3). The findings suggested that teachers do indeed have a set of complex belief systems that are sometimes not reflected in their classroom practices for various complicated reasons that some are directly related to context of teaching. Besides, beliefs are not context-specific and there are different beliefs within a particular context. Besides, it is possible that different contexts have similar beliefs (Horwits, 1999; and Bernat, 2006).

Castro (2010) has shown that individuals' experiences of cultural diversity affect their cultural beliefs. Gardner (1985) in his social-psychological model of language learning suggested that might be belief is an important factor to illustrate why some individuals perform so differently than the majority of learners in the same language-learning context (as cited in Hachfeld et al., 2011). Gardner (1985) argued that in spite of a number of intriguing group differences, it seems premature to conclude that beliefs about language learning vary by cultural groups. In contrast, the results point to the possibility that within group differences are likely to account for as much variation as the cultural differences (as cited in Horwitz, 1999). 
Tatto (1998) stated that there is little empirical evidence that teacher education can influence teachers' values or beliefs and findings of some researches (e.g. Weinstein (1989); Pravat (1992); and Lortie (1975)) showed that teacher education had little influence on teachers' beliefs and change in practices. Besides, changes in beliefs and practices are not generalizable to any teacher education or subject matter. Dunkin (2002) found that expert teachers were better able to identify important features of a task and to plan more quickly and efficiently because they are able to combine information from existing schemata to fit the particulars of a given lesson. Stuart and Thurlow (2000) argued that teacher education programs do not prepare teachers adequately. Novice teachers claimed that their undergraduate education programs do inadequately prepare them to face the demands of teaching in classrooms with increased numbers of children who do not speak English; children with inadequate family support for learning; students that unmotivated to learn; and students that alienated from school culture. They suggested that teachers beliefs about teaching form early in life and are highly resistant to change. These beliefs serve as filters for new information in a way that culturally held beliefs are frequently confirmed rather than confronted. These beliefs might impede the development of teachers capable of making substantive changes in classroom practices. Philips and Borg (2009) argued that contextual factors such as a prescribed curriculum, time constraints, and high-stakes examinations, mediate the extent to which teachers can act in accordance with their beliefs.

Donaghue (2003) pointed out teachers' beliefs influence the acceptance of new approaches, method, techniques, and activities, and therefore play a central part in teacher development. Consequently, teacher educators that handle teacher education programs should consider encouraging teachers to think about their personal beliefs and theories about teaching before providing input. Before any development, teachers' personal theories, beliefs, and assumptions need to be uncovered to enable critical reflection, and if needed, change them. Bernat and Gvozdenko (2005) stated that students' beliefs can be related to the nature of the language under study, the usefulness of various learning strategies, the length of time it takes to acquire a foreign language, the existence of language aptitude, and the effects of age and gender on second/foreign language acquisition among others. They suggested that these beliefs have the potential to influence teachers' attitudes and their motivation, and shape their experiences and actions in the classroom.

\subsection{Research Questions and Hypotheses}

The above mentioned studies were some of the numerous studies about different variables of multidimensional aspects of teachers' beliefs. The current study decides to investigate the relationship of some factors such as sex, experience, and context on teachers' beliefs about language teaching and their practices in Iranian EFL context.

To achieve the goals of the present correlational study, the following research questions were posed:

$\mathbf{Q}_{1}$ : Is there any relationship between state universities and different branches of Islamic Azad University ELT instructors' beliefs about language teaching and their real practices in the classrooms in Iran?

$\mathbf{Q}_{2}$ : Is there any relationship between ELT instructors' beliefs about language teaching in state universities and different branches of Islamic Azad University in Iran?

$\mathbf{Q}_{3}$ : Is there any relationship between ELT instructors' practices in state universities and different branches of Islamic Azad University in Iran?

$\mathbf{Q}_{4}$ : Is there any relationship between state universities and different branches of Islamic Azad University ELT instructors' teaching experience and their beliefs about language teaching and learning in Iran?

To come up with reasonable results based on the aforementioned research questions, the following null hypotheses were proposed:

$\mathbf{H 0}_{1}$ : There is no significant relationship between state universities and different branches of Islamic Azad University ELT instructors' beliefs about language teaching and their real practices in the classrooms in Iran.

$\mathbf{H O}_{2}$ : There is no significant relationship between ELT instructors' beliefs about language teaching in state universities and different branches of Islamic Azad University in Iran.

$\mathbf{H O}_{3}$ : There is no significant relationship between ELT instructors' practices in state universities and different branches of Islamic Azad University in Iran.

$\mathbf{H 0}_{4}$ : There is no significant relationship between state universities and different branches of Islamic Azad University ELT instructors' teaching experience and their beliefs about language teaching and learning in Iran. 


\section{Method}

\subsection{Participants}

To conduct the study, the researchers asked some Iranian ELT instructors for participation. To investigate what kinds of teaching beliefs are mostly interested among Iranian instructors and to what extent they put those beliefs into practice, the researchers used accidental sampling as proposed by Farhady (2006) and selected 369 Iranian instructors. The ages of instructors were in a range of 25 to 60 . One hundred and ten instructors $(29.8 \%)$ were less than 30 and 89 of them had more than 50 years of age. $45.8 \%$ of them were male and $54.2 \%$ were female. One hundred and fifty eight Iranian instructors (42.8\%) were teaching in state universities and $211(57.2 \%)$ in different branches of Islamic Azad University (IAU). The instructors participated in this study had different teaching experiences. Sixty nine of them $(18.7 \%$ ) had less than 5 years of teaching experiences, 152 five to 10 years, 108 instructors 11 to 20 , and $40(10.8 \%)$ had more than 20 years of teaching experiences. In addition to Iranian instructors, 512 Iranian EFL students also participated in this study. These students also were selected accidentally. Two hundred and twenty four of students (43.8 \%) enrolled in B.A. level and 288 (56.3 \%) in M.A. level.

\subsection{Procedures}

Teachers' Beliefs Questionnaire (TBQ) was distributed to Iranian ELT instructors in different universities such as state universities and different branches of Islamic Azad University through email. The researchers distributed the questionnaire to more than 800 instructors in offline/online format, from which, only 369 were returned (256 online and 113 offline). The same procedure was repeated for Iranian students and SSQ was distributed to university students of different provinces. From 900 distributed questionnaires, the researchers could get only 512 ones returned. To involve respondents from a larger number of cities in Iran, the researchers sent the questionnaires to some friends and colleagues in different cities. They administered the questionnaires to both instructors and students of different universities.

Then, a face-to-face semi-structured interview was conducted with nine instructors in 30 minutes. The interview was designed to encourage reflection and to elicit description and explanation about the participants' beliefs about English teaching. The interview outline was semi-structured in that the researchers had a list of topics and warm-up questions, but the participants were free to address other related topics if they liked.

Finally, the quantitative data were entered into a data file and analyzed statistically using the Statistical Package for Social Sciences (SPSS), version 18. Statistical analyses carried out on the data included Pearson product-moment correlation coefficient and Cronbach's alpha coefficient. Some collected data were qualitative. They included all open-ended responses to the interviews. The procedure for analyzing qualitative data was as follow: Each data set was read several times to gain some sense of the main ideas being expressed. Then, the data was coded and analyzed manually and subjectively.

\subsection{Instrumentations}

Due to the complex and unobservable characteristics of beliefs about language teaching, the present study was designed to use both quantitative and qualitative instrumentations to elicit data for the analysis.

To collect the required data, several instruments were employed in this study:

1. Teachers' Beliefs Questionnaire (TBQ). A researcher-made questionnaire was provided to elicit instructors' beliefs about language teaching. To make this questionnaire, the researchers obtained main ideas about language teaching from some researches such as Vibulphol (2004), Kim (2005), Mohamed, (2006), Awenowicz (2009), Liao (2007), Nishino (2008), Rieger (2009), Lin (2010), and Sage (2011). Three experts reviewed it for its content validity and reliability. Next, the collected data of TBQ were subjected to Principal Component Analysis (PCA) with varimax rotation to ensure its construct validity. Based on the results of running PCA, 23 items were omitted and the validated questionnaire comprised 40 items. The final version of TBQ was consisted of 40 Likert-scale items. Then, this researcher-made questionnaire was piloted with 50 instructors of the similar participants. Cronbach's Alpha formula for the inventory was employed; the results showed a reliability index of $0.74(\mathrm{r}=0.74)$. The main components of this questionnaire were the relationship between teacher and students, the process of language teaching, assessment, teachers' role, classroom management, classroom design, and parents' involvement.

2. Students' Satisfaction Questionnaire (SSQ). Students' Satisfaction Questionnaire (SSQ) was another researcher-made questionnaire and was very similar to the Teachers' Beliefs Questionnaire. This questionnaire was designed to elicit the instructors' practices in classrooms based on data collected from students. It contained 40 Likert- scale items that focused on instructors' practices in their language classrooms. In other words, SSQ 
was derived from TBQ and every item in the TBQ was reflected in SSQ. Through administration of this questionnaire among students, the researchers attempted to elicit the students' opinion about their instructors' practices in language classrooms. The scales used for identifying the intensity of every item were always, often, sometimes, rarely, and never. Students described their instructors' practices in classroom through some questions. This researcher-made questionnaire was also piloted with 50 students of the similar participants. Cronbach's Alpha formula for the inventory was employed; the results showed a reliability index of $0.85(\mathrm{r}=0.85)$.

3. Semi-structured interview. The researchers conducted a semi-structured interview with nine instructors to investigate in-depth information about teaching beliefs. In this face-to-face interview that was conducted in 30 minutes, the researchers began with lines of questioning and allowed the participants to address other related topics if they liked. The line of questioning was as follow: Beliefs and attitudes about teacher-centered and learner- centered methods; product-oriented and process-oriented designs; norm-referenced test (NRT) and criterion-referenced (CRT); teachers' role; classroom management; parents' involvement; and synthetic approach or analytic approach.

\section{Results and Discussions}

Having collected the required data based on the mentioned data collection instruments and procedures, the researchers conducted data analysis and tested the hypotheses formulated for the present study.

Table 1. Pearson Correlation of Instructors' Beliefs and Their Practices

\begin{tabular}{lll}
\hline Instructors' Practices & & \\
\hline \multirow{3}{*}{ Instructors' Beliefs } & Pearson Correlation & $.239^{* *}$ \\
\cline { 2 - 3 } & Sig. (2-tailed) & .000 \\
\cline { 2 - 3 } & $\mathrm{N}$ & 369 \\
\hline
\end{tabular}

Note. ${ }^{* *}$. Correlation is significant at the 0.01 level (2-tailed).

The relationship between Iranian ELT instructors' beliefs about language teaching (as measured by TBQ) and their practices in real classrooms (as measured by SSQ) was investigated using Pearson product-moment correlation coefficient. Preliminary analyses were performed to ensure no violation of the assumptions of normality and homoscedasticity. There was a small, positive correlation between the two variables, $\mathrm{r}=.239, \mathrm{n}=$ $369, \mathrm{P}<.000$, with higher sum of TBQ associated with higher sum of SSQ. The R value of .239 [ $(\mathrm{r}=.239$, $\mathrm{P}=.000<.05)]$ indicates that there is a statistically significant relationship between the two variables. Thus, the null-hypothesis as no significant relationship between instructors' beliefs about language teaching and the ways in which they act in their classrooms was rejected. As the results of Table 1 reveal, there is small positive relationship between instructors' beliefs and the ways in which they act in their classrooms.

Table 2. Pearson Correlation of Sum of TBQ for Instructors from ST \& IAU

\begin{tabular}{llc}
\hline SU \& IAU & & \\
\hline \multirow{2}{*}{$\begin{array}{l}\text { Instructors } \\
\text { Beliefs }\end{array}$} & Pearson Correlation & -.075 \\
\cline { 2 - 3 } & Sig. (2-tailed) & .362 \\
\cline { 2 - 3 } & $\mathrm{N}$ & 369 \\
\hline
\end{tabular}

The relationship between Iranian ELT instructors' teaching beliefs from State University (as measured by TBQ) and instructors' teaching beliefs from Islamic Azad University (as also measured by TBQ) was investigated using Pearson product-moment correlation coefficient. Preliminary analyses were performed to ensure no violation of the assumptions of normality and homoscedasticity. There was no significant correlation between the two variables, $\mathrm{r}=-.075, \mathrm{n}=150, \mathrm{P}<.362$. The $\mathrm{R}$ value of $.075[(\mathrm{r}=.075, \mathrm{P}=.362>.05)]$ indicates that there is no significant relationship between the two variables. Thus, the null-hypothesis as no significant relationship between ELT Iranian instructors' beliefs in different universities was accepted. As the results of Table 2 indicate, there is no significant relationship between instructors' beliefs in different universities.

To investigate the relationship between experience and ELT Iranian instructors' beliefs about language teaching, the researchers used Pearson product-moment correlation coefficient. 
Table 3. Pearson Correlation of State University and IAU Instructors' Practices

\begin{tabular}{lll}
\hline \multicolumn{3}{l}{ Islamic Azad University } \\
\cline { 2 - 3 } State & Pearson Correlation & $.262^{* *}$ \\
\cline { 2 - 3 } University & Sig. (2-tailed) & .000 \\
\cline { 2 - 3 } & $\mathrm{N}$ & 369 \\
\hline
\end{tabular}

Note. **. Correlation is significant at the 0.01 level (2-tailed).

The relationship between Iranian ELT instructors' practices from SU (as measured by SSQ) and instructors' practices from IAU (as measured by SSQ also) was investigated using Pearson product-moment correlation coefficient. Preliminary analyses were performed to ensure no violation of the assumptions of normality and homoscedasticity. There was a small, positive correlation between the two variables, $\mathrm{r}=.262, \mathrm{n}=224, \mathrm{P}<.000$, with higher sum of SSQ from ST associated with higher sum of SSQ from IAU. The R value of .262 [( $\mathrm{r}=.239$, $\mathrm{P}=.000<.05)]$ indicates that there is a statistically significant relationship between the two variables. Thus, the null-hypothesis as no significant relationship between Iranian ELT instructors' practices in different universities was rejected.

Table 4. Pearson Correlation of Sum of TBQ and Teaching Experience

\begin{tabular}{lll}
\hline Teaching Experience & & \\
\hline \multirow{3}{*}{ Instructors' Beliefs } & Pearson Correlation & $.481^{* *}$ \\
\cline { 2 - 3 } & Sig. (2-tailed) & .000 \\
\cline { 2 - 3 } & $\mathrm{N}$ & 369 \\
\hline
\end{tabular}

Note. **. Correlation is significant at the 0.01 level (2-tailed).

The relationship between teaching experience (as measured by TBQ) and Iranian instructors' teaching beliefs (as also measured by TBQ) was investigated using Pearson product-moment correlation coefficient. Preliminary analyses were performed to ensure no violation of the assumptions of normality and homoscedasticity. There was a medium and statistically significant correlation between the two variables, $\mathrm{r}=.481, \mathrm{n}=369, \mathrm{P}<.000$. The $\mathrm{R}$ value of $.481[(\mathrm{r}=.481, \mathrm{P}=.000<.05)]$ indicates that there is a significant relationship between the two variables. Thus, the null-hypothesis as no significant relationship between experience and Iranian instructors' beliefs about language teaching is rejected. As the results of Table 4 indicate, there is a medium and significant relationship between experience and Iranian instructors' beliefs about language teaching.

\section{Conclusions}

The collected data approved that there was a small and positive relationship between ELT instructors and their actions in the classrooms. The results of SSQ approved that instructors' practices were in accordance with what they claimed about language teaching in TBQs. Williams and Burden (1997) believed that teachers' beliefs have a major effect on their classrooms practices. The findings of present study confirmed this believes and demonstrated that there is positive relation between teachers' beliefs and their practices.

Nishino (2008) found that some contextual factors impede teachers to put their teaching beliefs into practice. The findings of interviews in the current study are consistent with those of Nishino (2008). In the interviews, instructors stated that if there is any discrepancy between beliefs and practices, it derives from barriers in educational settings. They argued that some barriers such as educational policy, financial issue, lack of enough materials, unmotivated learners, mismatched beliefs between teachers and students prevent effective teaching. Philips and Borg (2009) argued that contextual factors such as a prescribed curriculum, time constraints, and high-stakes examinations, mediate the extent to which teachers cannot act in accordance with their beliefs. Concordance with claims of Philips and Borg (2009), Iranian instructors in the interviews argued that contextual factors such as educational policy and prescribed curriculums circumscribe instructors to select their preferred teaching approaches, methodologies, designs, or even their evaluations in the classrooms. They asserted that in such circumstances, the role of teachers is limited and they have to follow prescribed curriculums. In addition, they cannot be creative and reflective in their teaching processes.

Esteve (2000) stated that many different and complex factors influence the roles teachers adopt in the classrooms. In the interviews, Iranian instructors supported this idea and criticized that the public believe teachers are 
directly responsible for the present state of affairs and the failings of the present-day teaching. Horwitz (1999) demonstrated that there are different beliefs and practices even within context with the same culture. He argued that beliefs are not context-specific. In contrast to Horwitz's (1999) findings, however, no evidence of difference between State University and IAU instructors' practices was detected. As the results indicated, there is a small and positive relationship between instructors' practices in different universities.

Investigating the relationship between experience and Iranian ELT instructors' beliefs about language teaching, the research demonstrated that there is a medium and significant relationship between experience and Iranian instructors' beliefs about language teaching. Evrim et al. (2009) pointed out that experienced teachers are more capable in instructional management than novice teachers. This also accords with earlier findings in this study which showed that there is a medium and significant relationship between experience and Iranian instructors' beliefs about language teaching and their practices.

The results of interviews demonstrated that Iranian instructors considered parents' involvement as an intervening factor in language teaching. In contrast, Gardner and Smythe (1975) documented that parents play an active role by monitoring their children's activities (as cited in Ellis 2008). Carter and Nunan (2001) also stated that parents link schools to home and provide full time environment for language learning, but Iranian instructors argued that parents mostly do not believe in teachers and their abilities. Parents guide their children based on their own beliefs about teaching that raise many unanticipated problems for teachers and lead their children to a state of confusion.

The results of this study can give some hints to educational scholars to put more time on teachers' beliefs for growth of the students in general and language learners in specific. The results demonstrated that teachers' beliefs play a role in how information on teaching is translated into classroom practices; therefore, understanding teachers' beliefs is essential for improving teaching practices and teacher education programs. Due to the nature of this study, it would be impossible to track changing in teachers' beliefs. Therefore, a longitudinal study could determine teachers' beliefs change over time. Furthermore, this study focused on Iranian instructors, conducting this study with different participants from different contexts and different universities with different ages, different fields of study, and different levels of education would be considerable in future studies.

\section{Acknowledgements}

We would like to express our deepest gratitude to Marzieh Khademi, whose encouragement and supports (e.g., providing language help, writing assistance, and statistical help) were a great merit throughout this study.

\section{References}

Awenowicz, M. A. (2009). The influence of beliefs and cultural models on Teacher candidates' professional identities and practices. Unpublished doctoral dissertation, University of Pittsburgh- Pittsburgh.

Bernat, E. (2006). Assessing EAP learners' beliefs about language learning in the Australian context. Asian EFL Journal Quarterly, 8(2), 202-227.

Bernat, E., \& Gvozdenko, I. (2005). Beliefs about language learning: current knowledge, pedagogical implications, and new research directions. TESL-EJ, 1(9), 1-21.

Borg, M. (2001). Key concepts in ELT teachers' beliefs. ELT Journals, 55(2), 186-188.

Branden, K. V. D. (2006). Task-based language education: From theory to practice. New York: Cambridge University Press.

Brown, H. G. (2001). Teaching by principles: An interactive approach to language pedagogy (2nd edition). NY: Pearson Education.

Carter, R., \& Nunan, D. (2001). The Cambridge guide to teaching English to speakers of other languages. Cambridge University Press.

Donaghue, H. (2003). An instrument to elicit teacher's beliefs and assumptions. ELT Journals, 57(4), 344-351.

Dunkin, J. M. (2002). Novice and award-wining teachers' concepts and beliefs about teaching in higher education: effectiveness, efficacy, and evaluation. Teacher thinking, beliefs, and knowledge in higher education, 41-57.

Ellis, R. (2008). The study of second language acquisition (2nd ed). Oxford: Oxford University Press.

Esteve, J. M. (2000). The transformation of the teachers' role at the end of the twentieth century: New challenges for the future. Educational Review, 52(2), 197-207. 
Evrim, A. E., Gökçe, K., \& Enisa, M. (2009). Exploring the relationship between teacher beliefs and styles on classroom management in relation to actual teaching practices: A case study. Procedia Social and Behavioral Sciences, 1, 612-617. http://dx.doi.org/10.1016/j.sbspro.2009.01.109

Fahim, M., \& Samadian, T. (2011). Sensory style preference of EFL students in Iran. Theory and Practice in Language Studies, 1(6), 644-65. http://dx.doi.org/10.4304/tpls.1.6.644-651

Farrell, C. S. T., \& Particia, C. P. L. (2005). Conceptions of grammar teaching: A case study of teachers' beliefs and classroom practices. TESL-EJ Top, 2(9), 1-13.

Hachfeld, A., Hahn, A., Schroeder, S., Anders, Y., \& Stanat, P. (2011). Assessing teachers' multicultural and egalitarian beliefs: The teacher cultural beliefs scale. Teaching and Teacher Education, 27, 986-996, http://dx.doi.org/10.1016/j.tate.2011.04.006

Hewitt, D. (2008). Understanding effective learning: Strategies for the classroom. New York: McGraw-Hill Education.

Horwitz, K. E. (1999). Cultural and situational influences on foreign language learners' beliefs about language learning: A review of BALLI studies. System, 27, 557-576.

Kennedy, M. M. (1997). Defining an ideal teacher education program. NCATE.wpd, Michigan State University, $1-29$.

Kim, R. K. (2005). Teacher beliefs and practices survey: Operationalizing the 1997 NAEYC guidelines. Unpublished doctoral dissertation, Louisiana State University- Louisiana.

Liao, P. (2007). Teachers' beliefs about teaching English to elementary school children. English Teaching \& Learning, 31(1), 43-76.

Lin, H. C. (2010). A case study: An ESL teacher's beliefs and classroom practices in grammar instruction. Unpublished doctoral dissertation, Minghsing University of Science and Technology.

Mansour, N. (2009). Science teachers' beliefs and practices: issues, implications, and research agenda. International Journal of Environmental \& Science Education, 4(1), 25-48.

Mohamed, N. (2006). An exploratory study of the interplay between teachers' beliefs, instructional practices, \& professional development. Unpublished doctoral dissertation, University of Auckland- Auckland.

Nishino, T. (2008). Japanese secondary school teachers' beliefs and practices regarding communicative language teaching: an exploratory survey. JALT Journal, 30(1), 27-51.

Philips, S., \& Borg, S. (2009). Exploring tensions between teachers' grammar teaching beliefs and practices. System, 37, 380-390. http://dx.doi.org/10.1016/j.system.2009.03.002

Sage, C. M. (2011). Learner beliefs in South Korea: Enriching the description. Electronic Journal of Foreign Language Teaching, 8(2), 216-233. Retrieved from http://e-flt.nus.edu.sg/

Schon, D. (1983). The Reflective Practitioner. London: Basic Books.

Stuart, C., \& Thurlow, D. (2000). Making it their own: pre-service teachers' experiences, beliefs, and classroom practices. Journal of teacher education, 2(51), 113-121.

Tatto, T. M. (1998). The influence of teacher education on teachers' beliefs about purposes of education, roles, and practice. Journal of teacher education, 49(1), 66-78.

Tsui, M. B. A. (2003). Understanding expertise in teaching: Case studies of second language teachers. New York: Cambridge University Press.

Vibulphol, J. (2004). Beliefs about language learning and teaching approaches of pre-service EFL teachers in Thailand. Unpublished doctoral dissertation, Chulalongkorn University- Bangkok, Thailand.

Williams, M., \& Burden, L. R. (1997). Psychology for language teacher: A social constructivist approach. Cambridge University Press. 